\title{
Influence of Ultraviolet Light Coupled with Hydrogen Peroxide Treatment on Organic Nitrogen and Carbon Precursors and Disinfection By-Product Formation
}

\author{
Huei-Wen Chen, Chia-Yang Chen, and Gen-Shuh Wang * \\ Institute of Environmental Health, National Taiwan University, Taipei, Taiwan.
}

Received: December 24, 2009 Accepted in revised form: March 6, 2010

\begin{abstract}
This study examined the relationships between organic matter composition and disinfection by-product formation potential (DBPFP) following water chlorination. Laboratory synthetic water with various compositions of organic carbon and nitrogen were treated with ultraviolet light, coupled with hydrogen peroxide $\left(\mathrm{UV} / \mathrm{H}_{2} \mathrm{O}_{2}\right)$, to assess the effects of $\mathrm{UV} / \mathrm{H}_{2} \mathrm{O}_{2}$ on their DBPFPs. Biologically treated wastewater effluent and histamine dihydrochloride were spiked in the tested solutions to represent complex organic matter compositions and nitrogenated aromatic structure. It was found that carbon-containing precursors were relatively easier to mineralize by $\mathrm{UV} / \mathrm{H}_{2} \mathrm{O}_{2}$ treatment than the nitrogen-containing compounds. $\mathrm{UV} / \mathrm{H}_{2} \mathrm{O}_{2}$ processes successfully reduced the precursors of trihalomethanes and haloacetic acids (HAAs); however, the treatment efficiency was lower for $N$-nitrosodimethylamine (NDMA) precursors. It was also observed that the degree of precursor removal was reduced when raw water was contaminated by domestic wastewater effluents. In comparison to untreated water, $\mathrm{UV} / \mathrm{H}_{2} \mathrm{O}_{2}$-treated water produced a higher ratio of HAAs than trihalomethanes after chlorination. This suggests that a higher fraction of hydrophilic compounds was obtained after $\mathrm{UV} / \mathrm{H}_{2} \mathrm{O}_{2}$ treatment. Raw water impaired by wastewater effluent also altered the formation and species distribution of DBPs, because higher ratio of HAAs and brominated DBPs were observed.
\end{abstract}

Key words: $\mathrm{UV} / \mathrm{H}_{2} \mathrm{O}_{2}$; dissolved organic nitrogen; nitrosodimethylamine; DBPFP; photodegradation

\section{Introduction}

D ISINFECTION IS USED to provide sufficient control over bioactivities in potable water treatments. However, during the process, organic matters that are already present in water may react with chlorine and/or chloramines to form various carcinogenic disinfection by-products (DBPs). Thus, the application of chlorine to water containing high levels of natural organic matters (NOMs) would elevate DBP formation and may pose potential health concerns. In addition to conventional DBPs, new generations of DBPs such as nitrosamines and iodinated trihalomethanes (THMs) were found with substantial toxicity at low concentrations in drinking water treated with distinct disinfectants (Richardson, 2003; Krasner et al., 2006). Consequently, the need to control DBP precursors became a crucial issue in ensuring the safety of drinking water.

The structure and functional groups of NOM may affect DBP formation. As a result, the prediction of DBP formation based on dissolved organic carbon (DOC) removal may not be

${ }^{*}$ Corresponding author: Institute of Environmental Health, National Taiwan University, 17 Xu-Zhou Road, Room 734, Taipei 10055, Taiwan. Phone: 886-2-33668098; Fax: 886-2-23940612; E-mail: gswang@ntu.edu.tw sufficient. The sources of NOM in water can be categorized into fractions, allochthonous and autochthonous (Westerhoff and Mash, 2002). In areas where raw water was contaminated by wastewater effluent discharge, because of anthropogenic activities, higher levels of nitrogenous organics were present in the water. The elemental composition of wastewater effluent is similar to that of autochthonous substances, with considerable higher concentrations of pesticides, detergents, pharmaceuticals, and personal care products. Wastewater effluents that impair allochthonous NOMs pose a great threat to drinking water quality because of their high chlorine demands and formation of emerging DBPs such as $N$ nitrosodimethylamine (NDMA).

NDMA is a potent carcinogen. In some water systems, where wastewater-contaminated raw water is used and monochloramine was applied as the disinfectant, higher concentrations of NDMA were observed in the treated water. Choi and Valentine (2002) reported that dimethylamine (DMA) with the presence of dissolved oxygen and ammonia in water produced NDMA and various by-products after chlorination through the formation of unsymmetrical dimethyl hydrazine. Further studies have revealed that strong oxidants such as ozone, chlorine dioxide, and hydrogen peroxide $\left(\mathrm{H}_{2} \mathrm{O}_{2}\right)$ react with DMA to form NDMA (Andrzejewski 
and Nawrocki, 2007). Other precursors that may also account for NDMA yields after disinfection may include NOM and substances with tertiary amines and dimethyl groups in wastewater (Gerecke and Sedlak, 2003; Lee et al., 2007).

Advanced oxidation process is a powerful technique that uses highly reactive hydroxyl radicals to mineralize organic contaminants via hydrogen atom removal or electrophile addition to double bonds. Among various advanced oxidation processes, the process of homogeneous photodegradation using ultraviolet light coupled with $\mathrm{H}_{2} \mathrm{O}_{2}\left(\mathrm{UV} / \mathrm{H}_{2} \mathrm{O}_{2}\right)$ had been widely studied for the control of various contaminants. Many researchers have employed the $\mathrm{UV} / \mathrm{H}_{2} \mathrm{O}_{2}$ process to treat organic and inorganic chemicals in industrial wastewater (Singer, 1999; Rodriguez et al., 2007; Bandy et al., 2009). In the Netherlands, the $\mathrm{UV} / \mathrm{H}_{2} \mathrm{O}_{2}$ process has been introduced to a large-scale drinking water treatment plant for the control of micropollutants (Kruithof et al., 2007).

Efficiency for the treatment of certain target compounds and humic substances on DBP formation with $\mathrm{UV} / \mathrm{H}_{2} \mathrm{O}_{2}$ were discussed in several studies (Singer, 1999; Rodriguez et al., 2007; Wert et al., 2007). However, very few reports are available concerning the influences of $\mathrm{UV} / \mathrm{H}_{2} \mathrm{O}_{2}$ on nitrogenous organic matters in the aqueous environment (Bandy et al., 2009). The objective of this study was to investigate the feasibility of $\mathrm{UV} / \mathrm{H}_{2} \mathrm{O}_{2}$ treatment for DBP precursors in water contaminated by domestic wastewater. To address the goal, $\mathrm{UV} / \mathrm{H}_{2} \mathrm{O}_{2}$ bench-scale studies were carried out to compare the degradation efficiency of DOC and dissolved organic nitrogen (DON) from distinct compositions. This study also attempted to elucidate the influences of $\mathrm{UV} / \mathrm{H}_{2} \mathrm{O}_{2}$ on trihalomethane formation potential (THMFP), haloacetic acid formation potential (HAAFP), and nitrosodimethylamine formation potential (NDMAFP), by varying the carbon and nitrogen contents in synthetic raw water.

\section{Materials and Methods}

\section{Photoreactor apparatus}

An 8-L stainless-steel UV reactor was used for photolysis experiments in this study. The $\mathrm{UV} / \mathrm{H}_{2} \mathrm{O}_{2}$ photooxidation was performed by employing a 450-watt high-pressure mercury UV lamp (Hanovia; Ace Glass Co), followed by the addition of $3.26 \mathrm{mM}(0.1 \%) \mathrm{H}_{2} \mathrm{O}_{2}$ in solution. The UV lamp was placed in the center of the reactor and was warmed up for $10 \mathrm{~min}$ before each experimental batch in order to reach a steady UV output. A water-cooling quartz tube was used to house the UV lamp and to protect it from overheating. The UV reactor was placed in a water bath to maintain the solutions at room temperature. A detailed description of the UV reactor can be found elsewhere (Wang et al., 2006).

\section{Reagents}

Water from the eco-pond at the National Taiwan University campus (Taipei, Taiwan) and biologically treated wastewater effluent from Neihu Wastewater Treatment Plant (Taipei, Taiwan) were selected to prepare solutions containing organic carbon and nitrogen for the experiments. The ecopond water (with $\sim 2.0 \mathrm{mg} / \mathrm{L}$ of nonpergeable dissolved organic carbon [NPDOC]) was filtered through a $1-\mu \mathrm{m}$ ceramic filter to remove the particulate matter before use. Biologically treated wastewater effluent (after primary sedimentation, activated sludge process, and secondary clarification) served as organic matters with complex structures from human origins. Water quality parameters for treated wastewater effluents and eco-pond water used in this study are shown in Table 1. Samples of eco-pond water and treated effluent were collected in polyethylene containers and stored at $4{ }^{\circ} \mathrm{C}$ for further use. Commercial humic acid (HA) extract (Aldrich) was used to prepare the stock solution of NOM and was spiked in synthetic raw water to increase the organic carbon content. For photodegradation of organic nitrogen precursors, histamine dihydrochloride $\left(\mathrm{C}_{5} \mathrm{H}_{9} \mathrm{~N}_{3} \cdot 2 \mathrm{HCl}\right.$, with an aromatic amino group in its structure) was spiked in some solutions to represent a simple structure of DON compound and to also increase the organic nitrogen content. Reagents used in this study were reagent or certified grade, purchased from SigmaAldrich or Merck. The $\mathrm{pH}$ of the solutions ranged between $\mathrm{pH}$ 6.5 and 7.5, and all of the photolysis experiments were conducted without further $\mathrm{pH}$ adjustment.

\section{THM, HAA, and NDMA formation potential}

Formation potential of THM and HAA was determined as follows: the samples were spiked with sodium hypochlorite (20 mg/L as chlorine), buffered at $\mathrm{pH} 7.0$ with phosphate solution, and stored in headspace-free amber glass bottles at room temperature. After 7 days, $5 \mathrm{~mL}$ of each sample was drawn out for THM measurements, and the remainder was used for HAA analysis. The samples for HAA analysis were spiked with ammonium chloride to halt additional HAA formation, followed by acidifying to $\mathrm{pH} 2$ with sulfuric acid. The formation potential of NDMA was determined as described by Mitch et al. (2003). In general, samples were buffered and dosed with different dosages of monochloramine $(0.05$ and $2.0 \mathrm{mM})$ in amber glassware with a Teflon cap. Monochloramine solution was prepared freshly for daily use; its concentration was determined using the $N, N$-diethyl- $p$ phenylenediamine ferrous titrimetric method (Standard Method 4500-Cl F). The reaction condition and temperature for NDMAFP was the same as those for THMFP and HAAFP. Excess ascorbic acid was added to quench the reactions.

\section{Sample analysis}

In UV photooxidation experiments, samples were collected at different time intervals and then filtered with a $0.45-\mu \mathrm{m}$

Table 1. Summary of Water Quality Parameters of Treated Wastewater Effluent

\begin{tabular}{lcc}
\hline Parameters & Wastewater effluent & Eco-pond water \\
\hline $\mathrm{pH}$ & $6.53 \pm 0.18$ & $6.76 \pm 0.39$ \\
$\mathrm{SS}(\mathrm{mg} / \mathrm{L})$ & $6.63 \pm 2.14$ & - \\
$\mathrm{COD}(\mathrm{mg} / \mathrm{L})$ & $15.02 \pm 2.68$ & - \\
$\mathrm{Cl}(\mathrm{mg} / \mathrm{L})$ & $11.54 \pm 0.45$ & $4.43 \pm 0.02$ \\
$\mathrm{NH}_{4}^{+}(\mathrm{mg} \mathrm{N} / \mathrm{L})$ & $8.66 \pm 4.14$ & $0.62 \pm 0.02$ \\
$\mathrm{NO}_{3}{ }^{2-}(\mathrm{mg} \mathrm{N} / \mathrm{L})$ & $7.07 \pm 0.34$ & $0.07 \pm 0.10$ \\
$\mathrm{NO}_{2}{ }^{-}(\mathrm{mg} \mathrm{N} / \mathrm{L})$ & $0.79 \pm 0.02$ & $0.09 \pm 0.00$ \\
$\mathrm{SO}_{4}{ }^{2-}(\mathrm{mg} / \mathrm{L})$ & $9.02 \pm 0.15$ & $4.36 \pm 0.01$ \\
\hline
\end{tabular}

Bromide concentration in eco-pond water was under the detection limit $(<0.05 \mathrm{mg} / \mathrm{L})$. Bromide concentration in wastewater effluent was not available because of the complex matrix effects in treated wastewater effluent.

SS, suspended solids; COD, chemical oxygen demand. 
cellulose acetate membrane filter prior to further analysis. Samples for NPDOC determination were acidified with $\mathrm{HCl}$ and measured with a Shimazdu TOC-5000A system. DON concentration was calculated as the difference between total dissolved nitrogen (TDN) and the total inorganic nitrogen, as given in the following equation (Kranabetter et al., 2007):

$$
[\mathrm{DON}]=[\mathrm{TDN}]-\left[\mathrm{NO}_{3}^{-}-\mathrm{N}\right]-\left[\mathrm{NO}_{2}^{-}-\mathrm{N}\right]-\left[\mathrm{NH}_{4}^{+}-\mathrm{N}\right]
$$

Nitrate and nitrite concentrations were measured by a Dionex DX-120 ion chromatography with an IonPac AS4A-SC column. Ammonium concentration was measured by the indophenol blue method, using Merck Spectroquant ${ }^{\circledR}$ test kit (analogous Standard Method $4500-\mathrm{NH}_{3} \mathrm{D}$ ). TDN was determined by the Koroleff digestion method, with 2,6-dimethylphenol as an indicator. The absorbance of $\left[\mathrm{NH}_{4}{ }^{+}\right]$and [TDN] measurements were quantified with a $1-\mathrm{cm}$ quartz cell and a high-resolution double-beam spectrophotometer (Shimadzu UV 160A).

Four THMs were analyzed following EPA method 524.2 with gas chromatography/mass spectrometry (GC/MS, Agilent 6890GC/5970MSD), and the nine HAAs were analyzed with EPA method 552.3 by GC (Agilent 6890GC) with microelectron capture detector. Solid-phase microextraction was employed for the analysis of NDMA via headspace extraction from water. Concentration of NDMA was determined by a Varian 4000 GC/MS system (CP-3800 GC) coupled with a 4000 ion trap spectrometer (Varian).

\section{Result and Discussion}

\section{NPDOC removal}

Figure 1 shows the NPDOC degradation profile after $\mathrm{UV} / \mathrm{H}_{2} \mathrm{O}_{2}$ treatment using water with different compositions of organic carbon and nitrogen sources. To simulate source water with different degrees of pollution, various DON constituents were spiked in water. In these experiments, eco-pond water spiked with HA/histamine represents autochthonous and allochthonous organics from natural sources, respectively. Conversely, different portions of biologically treated wastewater effluents were used to spike the same eco-pond water to simulate polluted raw water. Samples were collected within a photolysis period of $60 \mathrm{~min}$ to evaluate their efficiency. The results showed that the NPDOC in solution increased in the first $5 \mathrm{~min}$ because of oxidation and breakdown of macromolecules, followed by a continuous decrease in the HA/histamine solutions (Fig. 1A). As a whole, all three experiments gave a similar trend, showing that $\mathrm{UV} / \mathrm{H}_{2} \mathrm{O}_{2}$ treatment can remove $30 \%-40 \%$ of NPDOC in $\mathrm{HA} /$ histamine solutions. The amino acid compound analogs used in this experiment were histamine dihydrochlorides, which contain three nitrogen atoms and one aromatic ring in their molecular structure. Histamine dihydrochloride provided both organic carbon and nitrogen and thus could also potentially be a target for hydroxyl radicals. In the $\mathrm{HA} /$ histamine solutions, initial NPDOC concentrations for all three solutions were adjusted to $5 \mathrm{mg} / \mathrm{L}$ by adjusting the HA concentrations. The results indicated that there were no apparent differences observed in the NPDOC removal profile between the solutions with different histamine concentrations. Distinctions found in the organic precursors did not affect the oxidation efficiency, as spiked histamine dihy- drochloride only contributed to the overall DOC in solution at $0-0.5 \mathrm{mg} / \mathrm{L}$. Histamine dihydrochloride only provided $13.8 \%$ of the total DOC $(0.83$ of $5.6 \mathrm{mg} / \mathrm{L})$, with a maximum dosage of DON at $0.5 \mathrm{mg} / \mathrm{L}$. Although histamine dihydrochloride was expected to mineralize easier than the humic content, the contribution of NPDOC degradation from histamine dihydrochloride was minor. In general, the profile of NPDOC degradation mainly reflected the decomposition of $\mathrm{HA}$ in these solutions.

In comparison, treated wastewater effluent was used to spike the eco-pond water as a complex DON contributor that represented anthropogenous pollutants. Two sets of wastewater were used in the experiments: the entire volume of treated effluent (WW) or the supernatant of treated effluent $(\mathrm{WW} / \mathrm{U})$, as indicated in Fig. 1B and C. The main difference between the two effluents was the amount of sludge, which was settled and absent in the WW/U water. The NPDOC degradation profile of WW solutions illustrated the same fluctuated pattern as for HA/histamine-spiked solutions

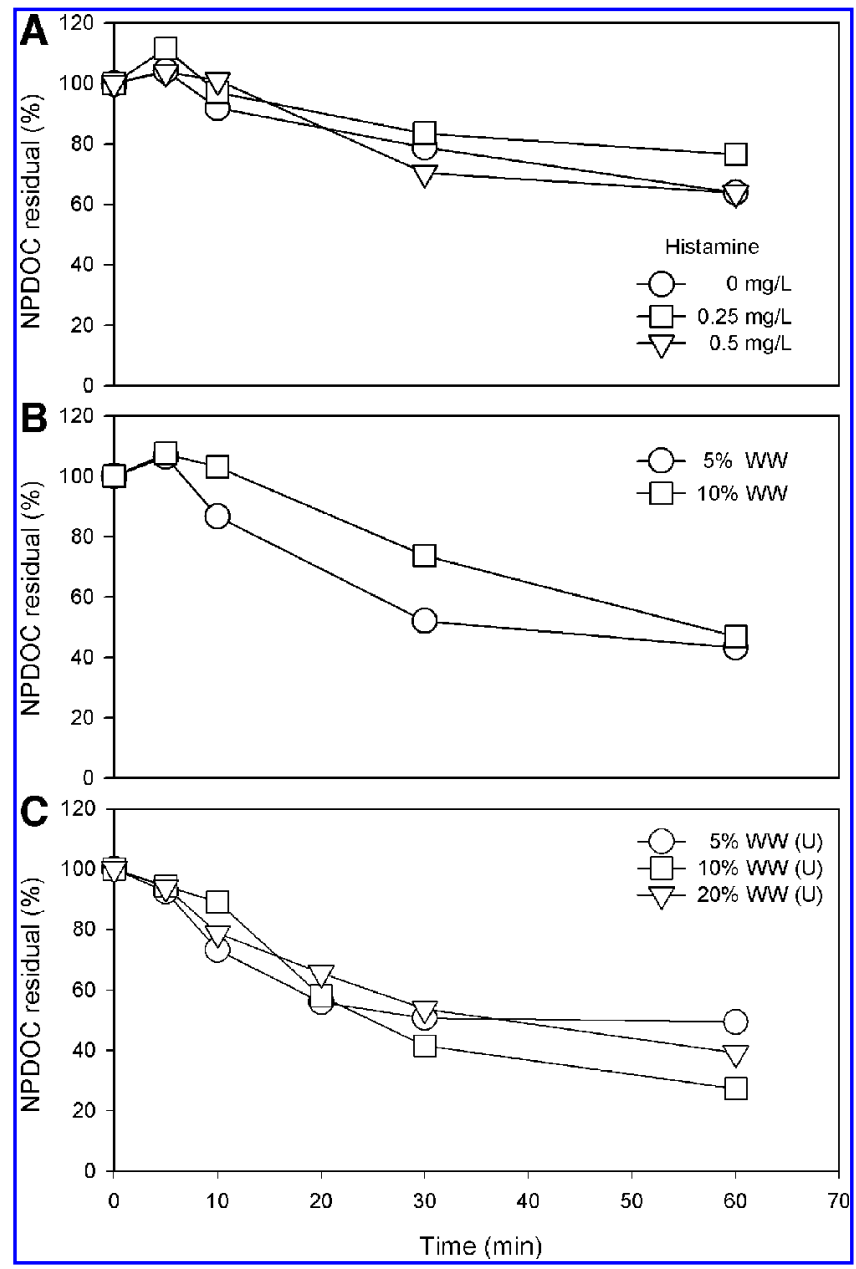

FIG. 1. Degradation profile of NPDOC in (A) eco-pond water spiked with humic acid and histamine $\left([\mathrm{NPDOC}]_{\mathrm{o}}=5 \mathrm{mg} / \mathrm{L}, \mathrm{pH}=7\right),(\mathbf{B})$ eco-pond water spiked with treated wastewater effluent $(\mathrm{WW})\left([\mathrm{NPDOC}]_{\mathrm{o}}=2\right.$ $3 \mathrm{mg} / \mathrm{L}, \mathrm{pH}=7$ ), and $(\mathbf{C})$ eco-pond water spiked with the supernatant of treated wastewater effluent (WW/U) $\left([\mathrm{NPDOC}]_{\mathrm{o}}=2-3 \mathrm{mg} / \mathrm{L}, \mathrm{pH}=7\right)$. NPDOC, nonpergeable dissolved organic carbon. 
within the first $10 \mathrm{~min}$. However, the total NPDOC degradation efficiency was improved to $50 \%$ after 60 min of oxidation. The results also indicated that WW/U-spiked solutions degraded faster in the first $30 \mathrm{~min}$ of photooxidation, and the NPDOC profile continuously dropped throughout the entire reaction period. By comparing the results with $\mathrm{WW} / \mathrm{U}$, substances in WW was found to contain more complex constituents with larger organic particulate such as sludges. These sludges can reach sizes greater than $0.45 \mu \mathrm{m}$ and cannot be measured in NPDOC analysis. In addition, such particles require more energy and contact time to completely mineralize. As the photolysis reaction proceeded, these sludge molecules were broken down to intermediates smaller in size and appeared in the NPDOC measurements.

\section{DON removal}

In HA/histamine solutions, DON components were from both amino acid and HA. The two nitrogen atoms on the aromatic ring of histamine allowed the nitroxides to oxidize easily. On the contrary, the complex structure of HA mole-

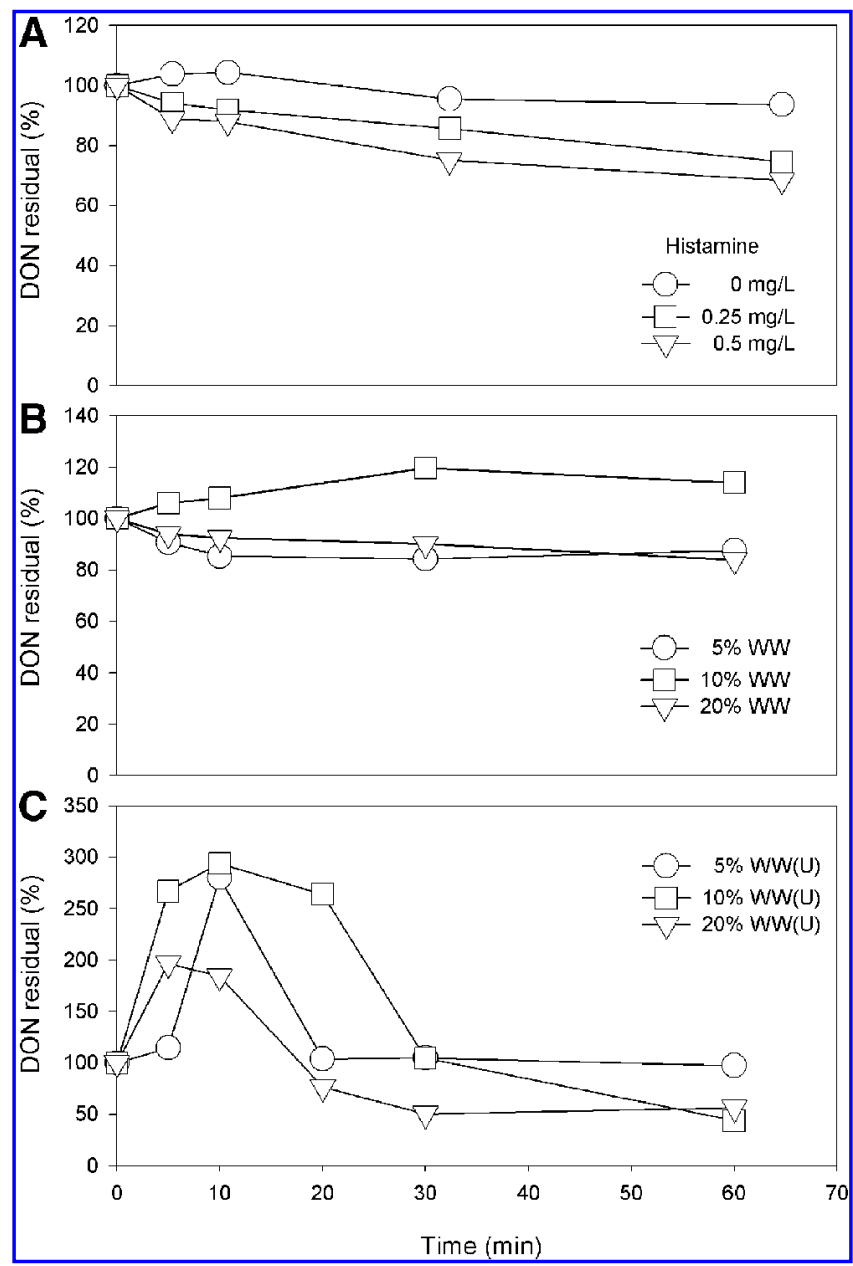

FIG. 2. Degradation profile of DON in (A) eco-pond water spiked with humic acid and histamine $\left([\mathrm{DON}]_{\mathrm{o}}=0.1-\right.$ $0.6 \mathrm{mg} / \mathrm{L}, \mathrm{pH}=7)$, (B) eco-pond water spiked with treated wastewater effluent $\left([\mathrm{DON}]_{\mathrm{o}}=0.8-1.8 \mathrm{mg} / \mathrm{L}, \mathrm{pH}=7\right)$, and (C) eco-pond water spiked with the supernatant of treated wastewater effluent $\left([\mathrm{DON}]_{\mathrm{o}}=0.4-1 \mathrm{mg} / \mathrm{L}, \mathrm{pH}=7\right) . \mathrm{DON}$, dissolved organic nitrogen. cules hindered complete mineralization. Thus, it was inferred that the decreasing DON was mainly due to the degradation of histamine molecules during UV photolysis. In Fig. 2A, the $\mathrm{HA}$ and organic matters from the bio-pond contributed to about $0.3 \mathrm{mg} / \mathrm{L}$ of DON. These substances were relatively hard to degrade when compared with the $0.5 \mathrm{mg} / \mathrm{L} \mathrm{DON}$ from histamine-spiked solution. In a comparative study involving $\mathrm{UV} / \mathrm{H}_{2} \mathrm{O}_{2}$ treatment of melanoidin, Dwyer and Lant (2008) reported that the DON removal was slower than DOC. The trends of $\mathrm{HA} /$ histamine DON residuals in Fig. 2A showed that solutions spiked with histamine dihydrochloride degraded faster during $\mathrm{UV} / \mathrm{H}_{2} \mathrm{O}_{2}$ oxidation. Figure $2 \mathrm{~B}$ also illustrated the influence of sludge in UV photolysis. As the upper layer of wastewater contained less macromolecule substances, the oxidation of organic matters in the $\mathrm{WW} / \mathrm{U}$ solutions was more efficient, thus resulting in a rapid DON increase in the first $20 \mathrm{~min}$. It has been shown that approximately $0.6 \%-13 \%$ of dissolved organic matters existed as combined amino acid in wastewater, and about $14 \%-25 \%$ was protein (Manka and Rebhun, 1982; Dignac et al., 2000). These substances can be broken down by hydroxyl radicals, which results in a gradual decline of DON, but the process can be obstructed by turbidity in the solution. When sludge was added to the solution, as shown in the WW solutions in Fig. 2B, the DON concentrations remained unchanged during photolysis. In summary, the existence of sludge particles

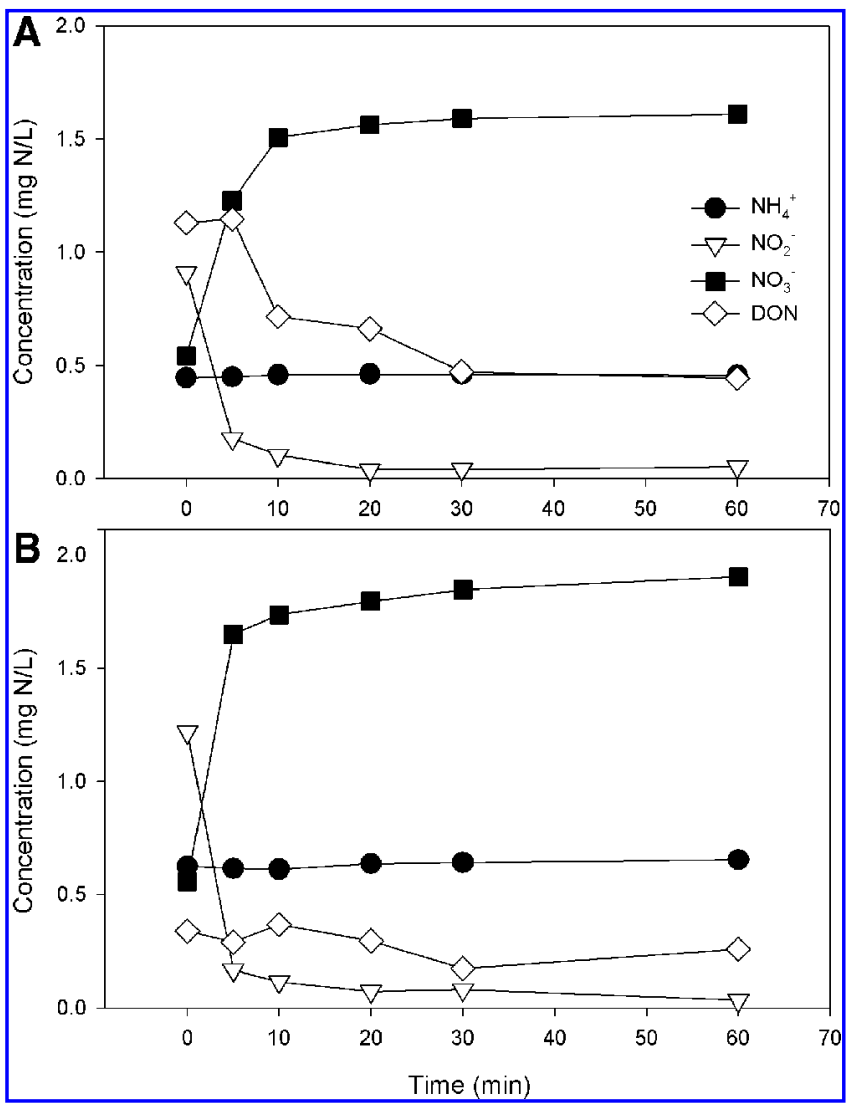

FIG. 3. Comparison of dissolved nitrogen species after $\mathrm{UV} / \mathrm{H}_{2} \mathrm{O}_{2}$ treatment in (A) eco-pond water spiked with $10 \%$ treated wastewater effluent and (B) eco-pond water spiked with $10 \%$ treated wastewater effluent and $1 \mathrm{~mL}$ of recycled sludge. $\mathrm{UV} / \mathrm{H}_{2} \mathrm{O}_{2}$, ultraviolet light coupled with $\mathrm{H}_{2} \mathrm{O}_{2}$. 
required a much longer reaction time or higher dosage of hydroxyl radicals to completely mineralize the nitrogencontaining substances in wastewater. It has been shown that complete decomposition of sludge can be achieved with enough contact time and an optimized oxidant dosage (Wang et al., 2001).

\section{Organic and inorganic nitrogen concentrations}

Figure 3 illustrates the variation of $\mathrm{DON}, \mathrm{NO}_{3}{ }^{-}, \mathrm{NO}_{2}{ }^{-}$, and $\mathrm{NH}_{4}{ }^{+}$concentrations during $\mathrm{UV} / \mathrm{H}_{2} \mathrm{O}_{2}$ oxidation. The initial turbidities of samples were 0.5 and 2.5 nephelometric turbidity units (NTU) in Fig. 3A and B, respectively. In general, $\mathrm{NH}_{4}{ }^{+}$was maintained at a relatively steady level during the reactions, whereas $\mathrm{NO}_{3}{ }^{-}$and $\mathrm{NO}_{2}^{-}$had different profiles. Compared with $\mathrm{NH}_{4}{ }^{+}, \mathrm{NO}_{2}{ }^{-}$was relatively easier to oxidize and resulted in an increase of $\mathrm{NO}_{3}{ }^{-}$. The sources of $\mathrm{NH}_{4}{ }^{+}$in treated water were generally from organic matters such as sludges and amino acids, which steadily oxidize and release $\mathrm{NH}_{4}{ }^{+}$. Because of the complex nature of these organic matters, the input and output of $\mathrm{NH}_{4}{ }^{+}$was maintained at a relatively steady level in this study. After UV photolysis, a 50\% DON reduction was achieved in the $10 \%$ wastewater-spiked solution, whereas the variation of DON was not significant when $1 \mathrm{~mL}$ of recycled sludge was spiked into the solution. As activated sludge from domestic wastewater contain higher nitrogen-containing substances with complex structures, higher oxidation power should be employed to obtain better treatment efficiency. This result also explained the increase of DON in Fig. 2B, where the DON concentration was contributed by incomplete mineralization.

\section{Formation of THMs and HAAs}

Figure 4A shows THMFP reduction of solutions spiked with different concentrations of histamine dihydrochloride. The addition of amino acid contributed $7.8 \%$ and $15 \%$ of total NPDOC, respectively. However, no apparent influence on THMFP was observed. This nitrogen-containing compound was considered highly chlorine demanding because of the reactive electrophilic group on this molecule (Hong et al., 2009). In addition, humic substances have been recognized as the primary precursors for THMs and HAAs (Singer, 1999). The humic contents in the tested solutions provided higher

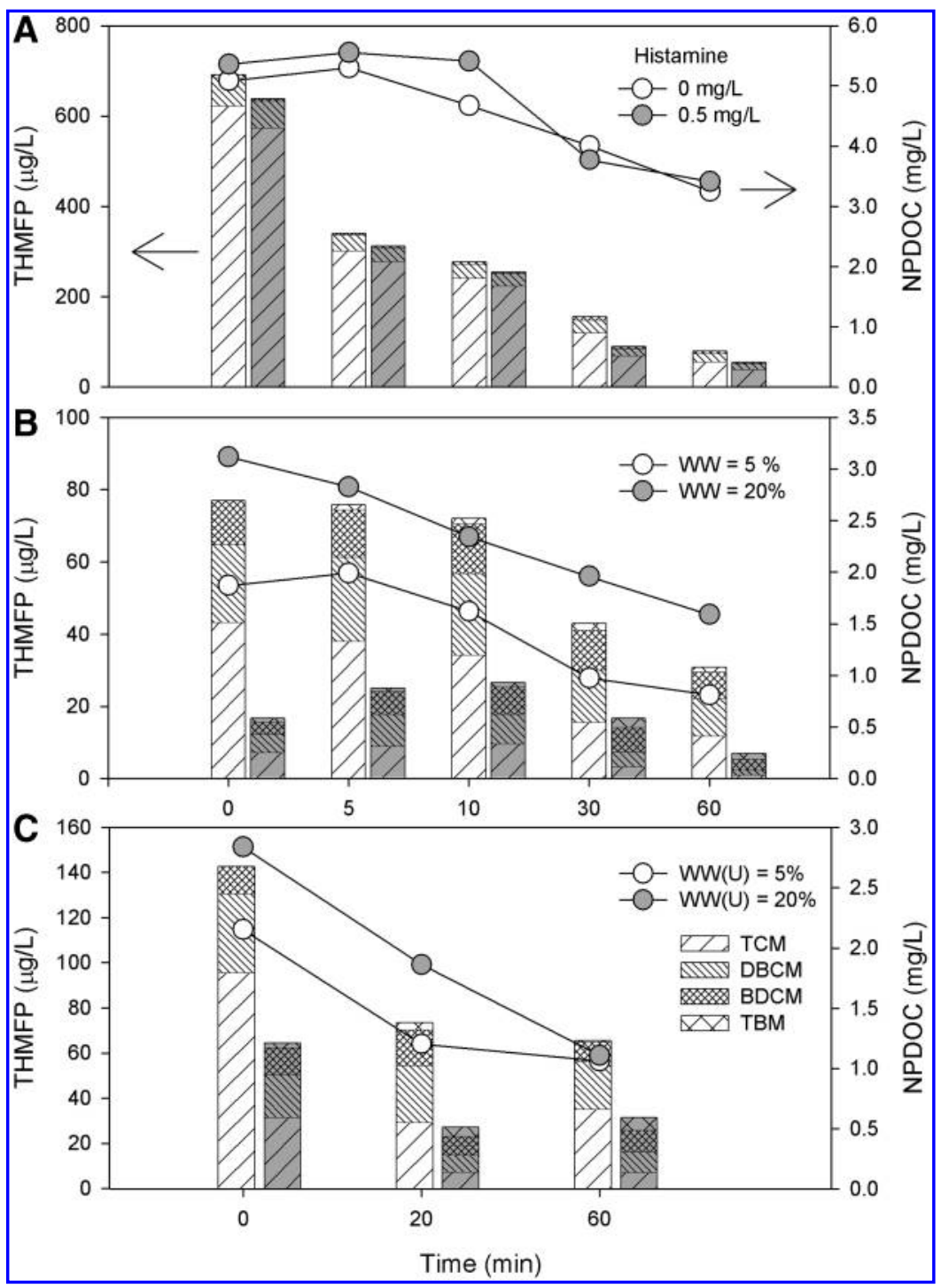

FIG. 4. Effect of $\mathrm{UV} / \mathrm{H}_{2} \mathrm{O}_{2}$ treatment on THMFP for solutions containing different sources of dissolved organic matter (DOM): (A) eco-pond water spiked with histamine and humic acid, (B) eco-pond water spiked with treated wastewater effluent, and (C) eco-pond water spiked with supernatant of treated wastewater effluent. The shaded symbols and bars indicate the solutions spiked with higher ratios of histamine, treated wastewater effluent, and supernatant of treated wastewater effluent in (A), (B), and (C), respectively. THMFP, trihalomethane formation potential. 
formation potential than amino acid in HA/histamine solutions, and the THMFP was expected to be proportional to NPDOC, mainly contributed by humic substances.

The addition of sludge in wastewater-spiked solution decreased the THMFP. The initial THMFP of solution with 5\% $\mathrm{WW}(\mathrm{U})$ was about two times higher than the 5\% WW-spiked solution $(142 \mu \mathrm{g} / \mathrm{L}$ and $76 \mu \mathrm{g} / \mathrm{L}$, respectively). When the WW(U)-spiked ratio was raised to $20 \%$, both the dissolved and particulate organic substances in the solutions were increased and the NPDOC elevated from 2 to $3 \mathrm{mg} / \mathrm{L}$. However, the THMFP was decreased to less than half of the value for the $5 \% \mathrm{WW}$ solution. The major reduction of the THMFP occurred after $30 \mathrm{~min}$ of photolysis and was slower than the NPDOC degradation. On the contrary, the THM and NPDOC concentration profiles varied inversely in the first $10 \mathrm{~min}$, as shown in Fig. 4B.

Chlorine could degrade organic substances and react with DBP precursors to form DBPs. As shown in Fig. 4C, when the concentration of organic matters reached a specific level, chlorine demand also increased and disinfection by-product formation potential (DBPFP) decreased when same amount of chlorine was added. After DBPFP tests, free chlorine residual was not detected in the $5 \%$ and $20 \% \mathrm{WW}$-spiked solutions. In addition, the amount of hydroxyl radicals could not provide sufficient oxidation power to completely mineralize the organic substances in $60 \mathrm{~min}$ of contact time in wastewaterspiked solutions (Fig. 2). As a result, the THMFP was decreased in high DOC and the sludge-containing solutions.

Figure 5A shows the HAAFP in $\mathrm{HA} /$ histamine and wastewater-spiked solutions. The results showed the same trend as observed for THMFP. Macrosludge particles and the high concentration of organic matters resulted in higher chlorine demand, thus leading to longer contact times for HAAFP removal. In comparison to THM precursors, HAA precursors in wastewater were more obstinate to be removed by $\mathrm{UV} / \mathrm{H}_{2} \mathrm{O}_{2}$ treatment. In the experiment using solution spiked with $20 \%$ of wastewater effluent, the THMFP decreased to $60 \%$, whereas the HAAFP was maintained at the same level after UV photolysis, as shown in Figs. 4B and 5B. This result suggests that HAA precursors in sludge were relatively more difficult to be eliminated than THM precursors. When particulate sludge was excluded, HAA precursor
FIG. 5. Effect of $\mathrm{UV} / \mathrm{H}_{2} \mathrm{O}_{2}$ treatment on HAAFP for solutions containing different sources of DOM: (A) eco-pond water spiked with humic acid/histamine, (B) eco-pond water spiked with treated wastewater effluent, and (C) eco-pond water spiked with supernatant of treated wastewater effluent. The shaded symbols and bars indicate the solutions spiked with higher ratios of histamine, treated wastewater effluent, and supernatant of treated wastewater effluent in (A), (B), and (C), respectively. HAAFP, haloacetic acid formation potential.

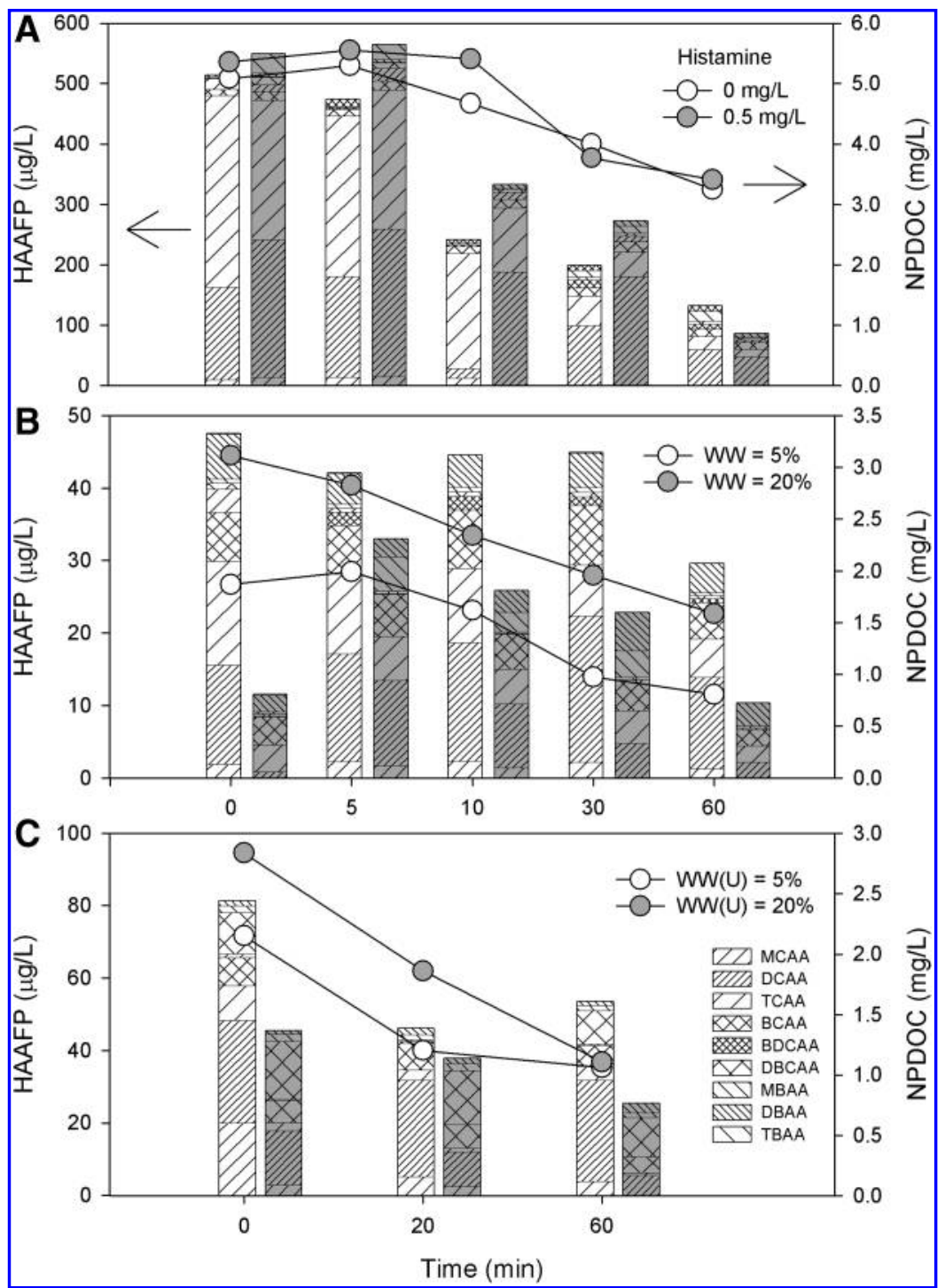




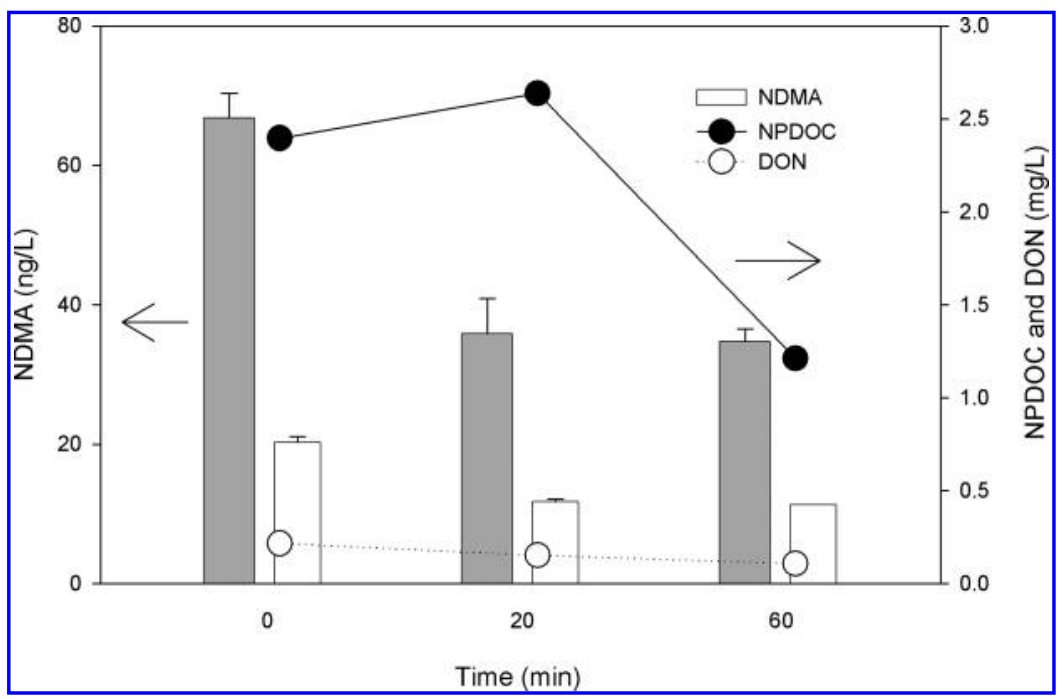

FIG. 6. Comparison of DOM and NDMAFP removal after $\mathrm{UV} / \mathrm{H}_{2} \mathrm{O}_{2}$ treatment. Chloramine dosages were $140 \mathrm{mg} / \mathrm{L}$ (gray bar) and $3.5 \mathrm{mg} / \mathrm{L}$ (white bar) in NDMAFP tests. NDMAFP, nitrosodimethylamine formation potential.

removal by hydroxyl radical was more effective. As shown in Fig. 5C, HAAFP decreased to $60 \%$ when compared with the untreated solution, and the HAAFP removal was close to that of THMFP.

In untreated $\mathrm{HA} /$ histamine solutions, the ratio of THMFP/HAAFP reduced from 1.5 to 0.5 after $\mathrm{UV} / \mathrm{H}_{2} \mathrm{O}_{2}$ treatment. The wastewater-spiked solutions demonstrated similar patterns, with the exception of the solution spiked with $20 \%$ settled wastewater effluent [WW(U)]. THMFP/HAAFP decreased from 2 to $0.5-1$ after UV photolysis, independent of the amount of sludge spiked. In Figs. $4 \mathrm{~B}$ and 5B, the THMFP and HAAFP show different trends even when the solutions had the same initial NPDOC concentration. The degradation products of the organic matters in wastewater tend to favor HAA formation over THM formation. As the volume of wastewater added to the solution increased, the ratio of HAAFP to THMFP also increased. When the ratio of wastewater spiked was raised from $5 \%$ to $20 \%$, the NPDOC was increased by $30 \%$, although the HAAFP/THMFP ratio also increased from 0.5 to 1 . This intriguing result suggested that the organic matters in wastewater may favor HAA formation. The change in HAAFP/THMFP ratios indicated that the distribution of hydrophilic/hydrophobic organics modified after UV photolysis, and the organic precursors became more hydrophilic and the HAAFP increased relatively. Similar results were observed in $\mathrm{TiO}_{2}$ photocatalysis of NOM (Liu et al., 2008), where considerably and slightly hydrophobic fractions of dissolved organic matter (DOM) decreased, thus resulting in the generation of hydrophilic compounds.

Following UV $/ \mathrm{H}_{2} \mathrm{O}_{2}$ treatment, the results in Figs. 4 and 5 showed that the proportion of bromine-containing DBPs increased in both $\mathrm{HA} /$ histamine and WW-spiked solutions. Here, the results suggested that after the photooxidation process, the structure of degraded organic matters were more feasible to react with $\mathrm{HOBr}$. This phenomenon was more apparent in wastewater-spiked solutions, and the proportion of brominated HAA species was raised higher than brominated THMs. DBP precursors frequently degraded into small, hydrophilic compounds after hydroxyl radical oxidation (Wang et al., 2006), and the organic constitution in wastewater with similar characteristics. This may favor the formation of HAAs after UV treatment.

\section{NDMA formation potential}

The effect of $\mathrm{UV} / \mathrm{H}_{2} \mathrm{O}_{2}$ treatment on NDMA precursor degradation was carried out by photooxidation of $10 \%(\mathrm{v} / \mathrm{v})$ wastewater-spiked solutions. Figure 6 depicts the results of NDMAFP for solutions before and after UV $/ \mathrm{H}_{2} \mathrm{O}_{2}$ treatment. For NDMAFP measurement, samples were dosed with 2.0 and $0.05 \mathrm{mM}$ of monochloramine for different molar ratios (monochloramine/DON). To exhaust all NDMA precursors, high dosage $(2.0 \mathrm{mM})$ of monochloramine was added, and the appropriate dosage used in the wastewater treatment plant was also studied by spiking $0.05 \mathrm{mM}$ of monochloramine. A correlation was observed in NDMAFP and DON concentrations, whereas NPDOC had no apparent influence on NDMAFP. The concentrations of NDMAFP and DON decreased significantly after $20 \mathrm{~min}$ of $\mathrm{UV} / \mathrm{H}_{2} \mathrm{O}_{2}$ treatment (50\% and $30 \%$ reduction, respectively), but there were no further degradation for NDMAFP. Despite the increase of NDMAFP with higher chloramine doses, the extent of NDMAFP was not in proportion to chloramination. The molar ratio of the two dosages was $40(2.0-0.05 \mathrm{mM})$, but NDMAFP was only three times higher for high monochloramine dosage. After $60 \mathrm{~min}$ of photolysis, 10-35 ng/L of NDMAFP was observed in the treated solutions. This result suggested that NDMA precursors remained in the solution even after $\mathrm{UV} / \mathrm{H}_{2} \mathrm{O}_{2}$ treatment.

\section{Conclusions}

$\mathrm{UV} / \mathrm{H}_{2} \mathrm{O}_{2}$ processes effectively mineralized the organic matter from natural and municipal sources. The existence of macroorganic molecules as sludge consumed more chlorine and hence reduced its oxidation efficiency. This observation was particularly obvious in DON decomposition with $\mathrm{UV} / \mathrm{H}_{2} \mathrm{O}_{2}$ treatment, compared with the $60 \%$ of NPDOC removal, where no major DON reduction was obtained. Because of the complex structure and composition of wastewater effluents, organic matters with higher oxidation demand reduced the efficiency of photooxidation, and the DBP precursors could only achieve a 50\% removal. Conversely, the DOC and DBPFP removals in HA solutions were significant when compared with the wastewater-spiked solutions. The THM and HAA precursor removal were $90 \%$ and $80 \%$, respectively, 
after UV $/ \mathrm{H}_{2} \mathrm{O}_{2}$ treatment. The DBPFP tests also showed that the organic substances in wastewater favored HAA formation, and $\mathrm{UV} / \mathrm{H}_{2} \mathrm{O}_{2}$ treatment enhanced this tendency. Bromide in raw water shifted the DBP species distribution to bromine-containing DBPs, and the phenomenon was more apparent in HAA formation after UV treatment. NDMAFP showed $\sim 50 \%$ removal after $\mathrm{UV} / \mathrm{H}_{2} \mathrm{O}_{2}$ treatment at different chloroamine dosages $(2 \mathrm{mM}$ : $68-34 \mu \mathrm{g} / \mathrm{L} ; 0.5 \mathrm{mM}$ : $20-11 \mathrm{ng} / \mathrm{L})$, and the NDMAFP was positively related to DON. However, no further DON and NDMAFP reduction can be obtained with additional and extended photolysis. This suggests that stronger oxidizing agent (higher dosages of $\mathrm{H}_{2} \mathrm{O}_{2}$ ) may be necessary to degrade more NDMA precursors.

\section{Acknowledgment}

This study was supported by the National Science Council, Taiwan, under grant no. NSC 97-2221-E-002-069.

\section{Author Disclosure Statement}

No competing financial interests exist.

\section{References}

Andrzejewski, P., and Nawrocki, J. (2007). N-nitrosodimethylamine formation during treatment with strong oxidants of dimethylamine containing water. Water Sci. Technol. 56, 125.

Bandy, J., Shemer, H., and Linden, K.G. (2009). Impact of lamp choice and $\mathrm{H}_{2} \mathrm{O}_{2}$ dose on photodegradation of nitrobenzene. Environ. Eng. Sci. 26, 973.

Choi, J.H., and Valentine, R.L. (2002). Formation of Nnitrosodimethylamine (NDMA) from reaction of monochloramine: a new disinfection by-product. Water Res. 36, 817.

Dignac, M.F., Ginestet, P., Rybacki, D., Bruchet, A., Urbain, V. and Scribe, P. (2000). Fate of wastewater organic pollution during activated sludge treatment: nature of residual organic matter. Water Res. 34, 4185.

Dwyer, J., and Lant, P. (2008). Biodegradability of DOC and DON for $\mathrm{UV} / \mathrm{H}_{2} \mathrm{O}_{2}$ pre-treated melanoidin based wastewater. Biochem. Eng. J. 42, 47.

Gerecke, A.C., and Sedlak, D.L. (2003). Precursors of Nnitrosodimethylamine in natural waters. Environ. Sci. Technol. 37, 1331.

Hong, H.C., Wong, M.H., and Liang, Y. (2009). Amino acids as precursors of trihalomethane and haloacetic acid formation during chlorination. Arch. Environ. Contam. Toxicol. 56, 638.
Kranabetter, J.M., Dawson, C.R., and Dunn, D.E. (2007). Indices of dissolved organic nitrogen, ammonium and, nitrate across productivity gradients of boreal forests. Soil Biol. Biochem. 39, 3147.

Krasner, S.W., Weinberg, H.S., Richardson, S.D., Pastor, S.J., Chinn, R., Sclimenti, M.J., Onstad, G.D., and Thruston, A.D. (2006). Occurrence of a new generation of disinfection byproducts. Environ. Sci. Technol. 40, 7175.

Kruithof, J.C., Kamp, P.C., and Martijn, B.J. (2007). UV $/ \mathrm{H}_{2} \mathrm{O}_{2}$ treatment: a practical solution for organic contaminant control and primary disinfection. Ozone Sci. Eng. 29, 273.

Lee, W., Westerhoff, P., and Croue, J.P. (2007). Dissolved organic nitrogen as a precursor for chloroform, dichloroacetonitrile, $\mathrm{N}$-nitrosodimethylamine, and trichloronitromethane. Environ. Sci. Technol. 41, 5485.

Liu, S., Lim, M., Fabris, R., Chow, C., Drikas, M., and Amal, R. (2008). $\mathrm{TiO}_{2}$ photocatalysis of natural organic matter in surface water: impact on trihalomethane and haloacetic acid formation potential. Environ. Sci. Technol. 42, 6218.

Manka, J., and Rebhun, M. (1982). Organic groups and molecular-weight distribution in tertiary effluents and renovated waters. Water Res. 16, 399.

Mitch, W.A., Gerecke, A.C., and Sedlak, D.L. (2003). A Nnitrosodimethylamine (NDMA) precursor analysis for chlorination of water and wastewater. Water Res. 37, 3733.

Richardson, S.D. (2003). Disinfection by-products and other emerging contaminants in drinking water. Trac-Trend. Anal. Chem. 22, 666.

Rodriguez, E., Peche, R., Merino, J.M., and Camarero, L.M. (2007). Decoloring of aqueous solutions of indigocarmine dye in an acid medium by $\mathrm{H}_{2} \mathrm{O}_{2} / \mathrm{UV}$ advanced oxidation. Environ. Eng. Sci. 24, 363.

Singer, P.C. (1999). Humic substances as precursors for potentially harmful disinfection by-products. Water Sci. Technol. 40, 25.

Wang, G.S., Chen, H.W., and Kang, S.F. (2001). Catalyzed UV oxidation of organic pollutants in biologically treated wastewater effluents. Sci. Total Environ. 277, 87.

Wang, G.S., Liao, C.H., Chen, H.W., and Yang, H.C. (2006). Characteristics of natural organic matter degradation in water by $\mathrm{UV} / \mathrm{H}_{2} \mathrm{O}_{2}$ treatment. Environ. Technol. 27, 277.

Wert, E.C., Rosario-Ortiz, F.L., Drury, D.D., and Synder, S.A. (2007). Formation of oxidation byproducts from ozonation of wastewater. Waer. Res. 41, 1481.

Westerhoff, P., and Mash, H. (2002). Dissolved organic nitrogen in drinking water supplies: a review. J. Water. Supply. Res. T. 51,415 . 